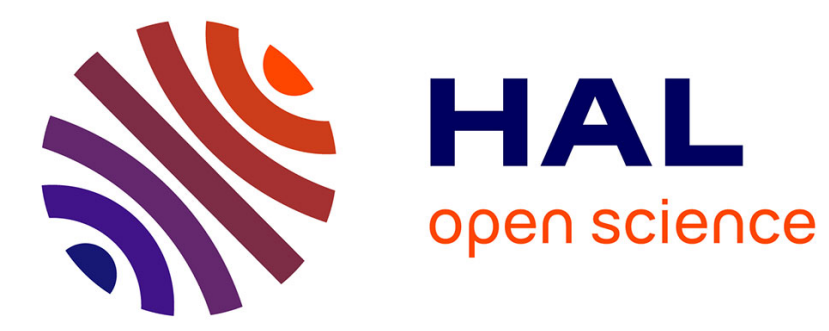

\title{
Are lutein, lycopene, and $\beta$-carotene lost through the digestive process?
}

\author{
Rachel E. Kopec, Béatrice Gleize, Patrick Borel, Charles Desmarchelier, \\ Catherine Caris-Veyrat
}

\section{- To cite this version:}

Rachel E. Kopec, Béatrice Gleize, Patrick Borel, Charles Desmarchelier, Catherine Caris-Veyrat. Are lutein, lycopene, and $\beta$-carotene lost through the digestive process?. Food and Function, 2017, 8 (4), pp.1494-1503. 10.1039/C7FO00021A . inserm-01499474

\section{HAL Id: inserm-01499474 https://www.hal.inserm.fr/inserm-01499474}

Submitted on 4 Apr 2018

HAL is a multi-disciplinary open access archive for the deposit and dissemination of scientific research documents, whether they are published or not. The documents may come from teaching and research institutions in France or abroad, or from public or private research centers.
L'archive ouverte pluridisciplinaire HAL, est destinée au dépôt et à la diffusion de documents scientifiques de niveau recherche, publiés ou non, émanant des établissements d'enseignement et de recherche français ou étrangers, des laboratoires publics ou privés. 
$1 \quad$ Are Lutein, Lycopene, and $\beta$-carotene Lost through the Digestive Process?

2

3 Rachel E. Kopec ${ }^{1,2,3}$, Béatrice Gleize ${ }^{1,2}$, Patrick Borel ${ }^{4 *}$, Charles Demarchelier ${ }^{4}$, Catherine Caris-

4 Veyrat $^{1,2 *}$

$5{ }^{1}$ INRA, UMR408, Sécurité et Qualité des Produits d'Origine Végétale, F-84000 Avignon,

6 France

$7 \quad$ 2Université d'Avignon et des Pays de Vaucluse, UMR408, Sécurité et Qualité des Produits

8 d'Origine Végétale, F-84000 Avignon, France

$9{ }^{3}$ Human Nutrition Program, The Ohio State University, Columbus, Ohio, U.S.A.

$10 \quad{ }^{4}$ Aix Marseille University, INRA, INSERM, NORT, Marseille, France

11

12 *Correspondence: Dr. Catherine Caris-Veyrat, phone: +33(0)4.32.72.24.89, email:

13 catherine.veyrat@avignon.inra.fr, fax: +33 (0)4.32.72.24.92; Dr. Patrick Borel, phone: +33 (0)4

14912941 11; fax: +33 (0)4 917821 01, email: patrick.borel@univ-amu.fr

15

16 Keywords: carotenoids, iron, metmyoglobin, in vitro digestion, metabolism, carotenoid

17 degradation

18

19

20

21

22

23

24

25

26

27

28

29

30 


\section{Abstract}

32 The bioavailability of many carotenoids has been assessed, but little attention has been given to

33 the metabolism of these antioxidant compounds during digestion. The isomerization and loss of

34 lutein, lycopene, and $\beta$-carotene incorporated into a lipid-rich liquid meal was determined in vitro

35 through the gastric, duodenal, and jejunal phases in the presence and absence of digestive enzymes,

36 and in the presence and absence of known oxidizing agents often found in mixed meals

37 (metmyoglobin in red meat and ferrous sulfate in supplemental iron). Carotenoids were quantitated

38 using HPLC-PDA. In the absence of enzymes, lutein and lycopene were lost during earlier phases

39 of the digestive process. In the presence of enzymes, lutein and lycopene were robust through the

40 gastric and duodenal phases, with statistically significant losses of $40 \%$ and $20 \%$, respectively,

41 observed only during the jejunal phase. Regardless of the presence or absence of enzymes, an

42 initial $25 \%$ of $\beta$-carotene was lost during the gastric phase, but no further loss was observed.

43 Ferrous sulfate had no significant impact on any carotenoid level. Metmyoglobin had no impact

44 on lutein, but significantly reduced lycopene and $\beta$-carotene levels by $30 \%$ and $80 \%$, respectively,

45 by the end of the jejunal phase. No significant isomerization was observed between the initial and 46 jejunal phases for any of the carotenoids.

47 


\section{Introduction}

The consumption of carotenoid-containing foods has been associated with a reduced risk of

50 developing a number of different types of diseases, such as various types of cancer ${ }^{1}$ and

51 cardiovascular disease. ${ }^{2}$ The contribution of oxidative stress to these and other chronic conditions

52 has been well established. ${ }^{3-5}$ Thus, for many years, the prevailing hypothesis was that carotenoids

53 absorbed from carotenoid-containing foods exerted antioxidant and singlet oxygen quenching

54 effects in vivo, ultimately leading to a reduction in chronic diseases. ${ }^{6-8}$

55 However, low carotenoid concentrations in areas where oxidative damage is a concern ${ }^{9}$, as well as

56 inconsistent results from high-dose clinical studies, have called into question the plausibility of

57 this hypothesis. ${ }^{10-12}$

58 In contrast, higher carotenoid concentrations found in the lumen of the gastrointestinal tract

59 (i.e. after the consumption of a carotenoid-containing meal) more convincingly support the theory

60 that these compounds may act as antioxidants in the gut. ${ }^{13,14}$ In fact, work from our group ${ }^{15-18}$ and

61 others ${ }^{19,20}$ has demonstrated the capacity of carotenoids to confer protection to unsaturated fatty

62 acids under gastric and micellar (i.e. duodenal-like) conditions. Carotenoids also have a

63 notoriously low bioaccessibility ${ }^{21}$ and bioavailability ${ }^{22}$ relative to other fat-soluble antioxidants

64 like tocopherols ${ }^{23}$ and omega-3-fatty acids. ${ }^{24}$ It is possible that at least a portion of this low

65 bioavailability may be due to loss of the carotenoid via oxidation during the digestive process.

66 Indeed, carotenoids are known to be sensitive to increased temperature, pro-oxidative species, and

67 an acidic $\mathrm{pH}$, three factors found during digestion. ${ }^{13,14}$ Furthermore, foods are consumed and co-

68 consumed in a multitude of combinations. The essential metal iron is present in various oxidation

69 states and complexes in the diet, and has also been shown to be a strong carotenoid oxidizing 
87 iron in red meat) were also investigated.

2. Materials \& Methods

agent. ${ }^{15}$ The oxidation effect of iron may be perpetuated in the presence of unsaturated fatty acids, where lipid peroxidation products can ultimately co-oxidize carotenoids in solution. ${ }^{16}$

There is still no prevailing consensus on the mechanism(s) of action of non-provitamin A carotenoids once absorbed in the human body. More recent theories suggest that carotenoids may serve as "pro-bioactives", i.e. the parent carotenoid consumed from a fruit or vegetable may be chemically or enzymatically converted into a biologically active metabolite(s) that ultimately exerts a disease-protective effect. ${ }^{25,26}$ This hypothesis is further supported by the fact that nonprovitamin A metabolites of the most commonly consumed carotenoids, i.e. $\beta$-carotene, lycopene, and lutein, have been identified in blood plasma and various fruits, vegetables, and food products. ${ }^{27-29}$ It is not clear if these products were 1) absorbed directly from the foods themselves, 2) formed during digestion, 3) formed after parent carotenoid absorption, or a combination thereof.

To better understand the fate of carotenoids during digestion, in vitro methods were employed to study carotenoid stability after each phase (initial, post-gastric, post-duodenal, and post-jejunal). Three of the most widely consumed carotenoids were chosen for study: lutein, $\beta$-carotene, and lycopene. Experiments were carried out both with and without digestive enzymes to better understand their influence. Finally, the impact of different dietary iron sources (i.e. ferrous sulfate commonly prescribed as an iron supplement, and metmyoglobin as the primary source of oxidized

2.1 Materials - For digestion experiments, food-grade lutein powder (product number 1EAA6165;

$9069 \%$ lutein by weight, as determined by molar extinction coefficient of all-trans lutein and HPLC-

91 PDA analysis; geometrical isomer breakdown: 95\% all-trans- and 5\% cis-lutein) and food-grade

92 lycopene-containing oleoresin (product number 1EAA9272; 4.5\% lycopene by weight as 
93 determined by molar extinction coefficient of all-trans-lycopene and LC-PDA analysis; 94 geometrical isomer breakdown: 78\% as all-trans-, $11 \%$ 5-cis- and 11\% other-cis-lycopene) were 95 kindly donated by Simona Birtic of Naturex (Montfavet, France). Fluka brand $\beta$-carotene $(\geq 97 \%$ 96 pure; geometrical isomer breakdown: $96 \%$ all-trans- and 4\% cis- $\beta$-carotene) from Sigma-Aldrich 97 (Saint-Quentin-Fallavier, France) was used both for digestion experiments and for analytical 98 quantitation. White granular sugar and $100 \%$ sunflower oil were purchased from a local 99 supermarket (Auchan, Avignon, France). Food-grade phospholipid (Ovolife IF 50, containing 50\% 100 w/w phospholipid derived from egg yolk with a maltodextrin excipient) was kindly donated by 101 Lecico, Inc. (Hamburg, Germany). Deionized water was obtained through filtration via a Millipore 102 Q-Plus. HPLC grade methyl tert-butyl ether (MTBE) and LC-MS grade methanol were purchased 103 from Fisher Scientific (Illkirch, France). Ammonium acetate ( $\geq 98 \%$ pure, reagent grade), pepsin 104 (pepsin A, from porcine gastric mucosa), bile extract (porcine origin), pancreatin (from porcine 105 pancreas), mucin (type III, from porcine stomach), $\alpha$-amylase (from Bacillus subtilis), myoglobin 106 ( $\geq 90 \%$ from equine heart), sodium chloride $(\mathrm{NaCl})$, sodium citrate tribasic dehydrate, sodium 107 bicarbonate, calcium chloride dihydrate, potassium phosphate, disodium 108 ethylenediaminetetraacetic acid (EDTA); Fluka brand potassium chloride, Extrasynthese brand 109 lycopene (analytical grade), and Sigma brand pyrogallol (>99\%) were purchased from Sigma110 Aldrich (Saint-Quentin-Fallavier, France). Hydrochloric acid (HCl) was purchased from VWR. 111 Tardyferon ${ }^{\circledR}$ was used as the source of ferrous sulfate (Boulogne, France). O-TRENSOX ${ }^{\circledR}$ (used 112 to chelate metmyoglobin ${ }^{30}$ ) was a kind gift from Gisele Gellon.

1132.2 Carotenoid in oil preparation for the test meals $-\beta$-Carotene $(2 \mathrm{mg})$ or powdered lutein (3.1

$114 \mathrm{mg}$ ) were added to $0.6 \mathrm{~g}$ sunflower oil, while the lycopene oleoresin (63 $\mathrm{mg}$ ) was combined with $1150.84 \mathrm{~g}$ sunflower oil. The oil mixtures were stirred overnight in the absence of light and under 
argon. Note that the quantity of each carotenoid-containing product mixed with oil was dosed to deliver approximately $1.0 \mathrm{mg}$ of carotenoid in $0.3 \mathrm{~g}$ oil.

2.3 Test meal preparation - Quantities of the test meal ingredients are shown in Table 1. Water and sugar were first mixed together in a beaker until the sugar was dissolved. The phospholipid containing powder (Ovolife IF 50) was added to the mixture and homogenized using a Heidolph Silent Crusher M (Schwabach, Germany) operated at 24,000 rpm for 2 min. Sunflower oil was then added and the mixture was again homogenized using the same conditions, followed by probe sonication using a Q700 QSonica (Newton, USA) with 40\% amplitude and 30 sec sonication followed by $30 \mathrm{sec}$ rest, repeated $8 \mathrm{x}$ in sequence. After the removal of $18 \mathrm{~mL}$ of solution (which served to provide 3 "control" meals), the carotenoid in oil was added to the test meal remaining in the beaker. The meal was again homogenized and probe sonicated as described before.

2.4 Ferrous sulfate $\left(\mathrm{Fe}^{I I}\right)$ solution - A Tardyferon ${ }^{\circledR}$ tablet containing $80 \mathrm{mg}$ of iron was powdered, and $20 \%$ of the final powder weight was added to $45 \mathrm{~mL}$ of a $0.9 \%$ aq. $\mathrm{NaCl}$ solution. The solution was homogenized for $30 \mathrm{sec}$ and then bath sonicated for $10 \mathrm{~min}$ to enhance dissolution (final concentration $=5.7 \mathrm{mM} \mathrm{Fe} / \mathrm{II} / 6 \mathrm{~mL}$ ).

2.5 Metmyoglobin $\left(\mathrm{MbFe}^{\mathrm{III}}\right)$ solution - The Sigma product myoglobin $\left(\mathrm{MbFe}^{\mathrm{II}}\right)$ was dissolved in water and tested via UV-Visible spectrometry to indeed confirm by $\lambda_{\max }$ that the product had been completely oxidized to metmyoglobin $\left(\mathrm{MbFe}^{\mathrm{III}}\right)^{31}$. $\mathrm{MbFe}^{\mathrm{III}}(21 \mathrm{mg})$ was dissolved in $10 \mathrm{~mL}$ of a $0.9 \%$ aq. $\mathrm{NaCl}$ solution (final concentration $=40 \mu \mathrm{M} \mathrm{MbFe} \mathrm{III}^{\mathrm{II}} / 2 \mathrm{~mL}$ ).

2.6 Inhibitor solutions - Inhibitor solutions were prepared to halt any further chemical degradation of the digesta samples during extraction. The pyrogallol solution (used to quench samples of the digesta of carotenoid alone) was prepared by dissolving $125 \mathrm{mg}$ pyrogallol in $25 \mathrm{~mL}$ water. The $\mathrm{Na}_{2}$ EDTA solution (to quench the carotenoid $+\mathrm{Fe}^{\mathrm{II}}$ digesta) was made by dissolving $140 \mathrm{mg}$ 
$139 \mathrm{Na}_{2}$ EDTA and $100 \mathrm{mg}$ pyrogallol in $20.2 \mathrm{~mL}$ of water. The O-TRENSOX® solution (to quench 140 carotenoid $+\mathrm{MbFe}^{\mathrm{III}}$ digesta) was made by dissolving $8.6 \mathrm{mg}$ O-TRENSOX® and $100 \mathrm{mg}$ 141 pyrogallol in $20.2 \mathrm{~mL}$ of water.

142 2.7 Digestion with enzymes - Following the initial in vitro digestion method of Garret et al. ${ }^{32}$, 143 modifications were made as previously described ${ }^{33}$, as well as the addition of a jejunal phase. Each 144 digestive condition with carotenoid was tested in triplicate, and the test beakers were placed on a 145 magnetic stir plate in an oven (in the absence of light) at $37^{\circ} \mathrm{C}$ during each phase. The digestions 146 were prepared by adding $6 \mathrm{~mL}$ of test meal (delivering $80 \mu \mathrm{g}$ carotenoid) to $32 \mathrm{~mL}$ of a $0.9 \%$ aq. $147 \mathrm{NaCl}$ solution (carotenoid alone), $30 \mathrm{~mL}$ of a $0.9 \%$ aq. $\mathrm{NaCl}$ solution containing $2 \mathrm{~mL}$ of the 148 149 the $\mathrm{Fe}^{\mathrm{II}}$ solution (carotenoid $\left.+\mathrm{Fe}^{\mathrm{II}}\right)$. The buccal phase $(10 \mathrm{~min})$, gastric and duodenal phases (each $15030 \mathrm{~min}$ ) were mimicked as previously described. ${ }^{33}$ The jejunal phase was mimicked by adjusting 151 the $\mathrm{pH}$ to 7 by adding $\sim 1.2 \mathrm{~mL} 0.9 \mathrm{M}$ aq. $\mathrm{NaHCO}_{3}$ and digesting for $30 \mathrm{~min}$. In addition, during the 152 duodenal and jejunal phases, the beaker headspace was backfilled with argon to displace any air 153 and thus any dioxygen molecules. Samples $(0.5 \mathrm{~mL})$ were taken immediately after the test meal 154 was added to the digestion beaker $(\mathrm{t}=0)$, and after the gastric, duodenal, and jejunal phases, and 155 quenched with an equivalent volume of their respective inhibitor solutions.

1562.8 Digestion without enzymes- The procedures were followed as described above, with the 157 exception that the respective digestion buffers alone were added in place of the buffers with 158 enzymes.

159 2.9 Sample extraction - To each sample already combined with inhibitor solution, methanol (0.5 $160 \mathrm{~mL})$ was added and the vial was shaken for 1 minute. Next, hexane was added ( $2 \mathrm{~mL})$, the sample 161 vortexed for $1 \mathrm{~min}$. The upper hexane phase was transferred to a clean glass vial, and 
162 dichloromethane $(2 \mathrm{~mL})$ was then added to the remaining sample. The sample was again vortexed 163 (1 $\mathrm{min}$ ), and then centrifuged for $2 \mathrm{~min}$ at 3,000 rpm (Jouan MR1822, ThermoFisher Scientific, 164 Walham, MA, U.S.A.) to induce a clean phase separation. The lower dichloromethane phase was 165 removed and pooled with the hexane extract and dried under a stream of argon at $30^{\circ} \mathrm{C}$. Dried 166 extracts were stored at $-20^{\circ} \mathrm{C}$ for no more than 2 days before analysis.

1672.8 HPLC Analysis - Extracts were redissolved in $50 \mu \mathrm{L}$ MTBE, to which $50 \mu \mathrm{L}$ of MeOH was 168 added and samples were briefly sonicated $(<5 \mathrm{sec})$ in a sonication bath for dissolution. Samples 169 were analyzed using an HP1100 (Agilent Technologies, Santa Clara, CA, U.S.A.) HPLC system 170 equipped with a photodiode array detector. Lutein and $\beta$-carotene samples were separated using a 171 YMC C30 column (150 mm x $2.0 \mathrm{~mm}, 3 \mu \mathrm{m}$ particle size) using a previously published liquid 172 chromatography method ${ }^{34}$ employing solvent $\mathrm{A}$ (80:18:2 MeOH/water/2\% aq. ammonium acetate) 173 and solvent $\mathrm{B}(20: 78: 2 \mathrm{MeOH} / \mathrm{MTBE} / 2 \%$ aq. ammonium acetate), but halting the gradient at 26 $174 \min$ and injecting $10 \mu \mathrm{L}$. Note that this method separated all-trans- $\beta$-carotene and all-trans-lutein 175 from cis geometrical isomers (9-cis- $\beta$-carotene was putatively determined by coincident PDA 176 spectra and elution order just after all-trans- $\beta$-carotene ${ }^{35}$, while all other cis-isomers of $\beta$-carotene 177 and all cis isomers of lutein were determined by PDA spectra and elution prior to the all-trans 178 configuration). Lycopene samples were separated using a method designed to partially separate 5179 cis-lycopene (which elutes just after the all-trans configuration on a C30 column ${ }^{36}$ ) from all-trans180 lycopene, as well as other cis-isomers (which elute prior to the all-trans configuration). A YMC 181 C30 column (150 mm x $4.6 \mathrm{~mm}, 3 \mu \mathrm{m}$ particle size) column was employed using the same solvent 182 system as above, with the following gradient: beginning at $40 \% \mathrm{~B}$, increasing linearly to $80 \% \mathrm{~B}$ 183 over $23 \mathrm{~min}$, holding at $80 \%$ B for $1 \mathrm{~min}$, returning to $40 \% \mathrm{~B}$ over $3 \mathrm{~min}$. The column was held at 184 a cooler temperature of $20^{\circ} \mathrm{C}$ (which afforded better separation of the lycopene isomers ${ }^{37}$ ), the 
185 flow rate was $1.3 \mathrm{~mL} / \mathrm{min}$, and $10 \mu \mathrm{L}$ samples were injected. Carotenoids were quantitated using external calibration curves generated from authentic standards by integrating the peak areas at 445 $\mathrm{nm}$ (lutein), $450 \mathrm{~nm}$ ( $\beta$-carotene), and $471 \mathrm{~nm}$ (lycopene). Total carotenoid calculated at each step incorporated any previous digesta volume change (with the addition of enzyme/buffer solution and previous sample removal) over the course of the experiment.

2.10 Statistical Analysis - Data was analyzed using R statistical software ${ }^{38}$. A mixed factorial design with repeated measures ANOVA was employed to test the fixed factors of meal (between subject factor with 3 levels consisting of control, metmyoglobin, and ferrous sulfate), digestion phase (within subject factor with 4 levels i.e. initial, gastric, duodenal, and jejunal), and meal*digestion phase, on carotenoid level (dependent variable). The error factor controlled for within flask variability. A $P$ value $<0.05$ was considered statistically significant. Post-hoc analysis was performed using the Bonferroni correction for multiple comparisons to determine statistically significant interactions within the same meal over multiple digestion phases, and between meals at the same digestion phase.

\section{Results}

Figure 1 reveals the loss of lutein in the 3 different meals during the course of in vitro digestion. In the absence of enzymes (Figure 1A), approximately $25 \%$ of the initial lutein was lost during the gastric phase regardless of the meal (i.e. control, metmyoglobin, or ferrous sulfate). During the duodenal and jejunal phases, no additional loss of lutein was observed with lutein alone or lutein + ferrous sulfate. Only in the presence of metmyoglobin was an additional $20 \%$ of lutein lost during the duodenal phase. Figure 1B reveals that lutein was more robust through the gastric and duodenal phases of digestion when enzymes were present, with no difference observed between conditions 
207 or phases. However, by the jejunal phase, the results mimicked that of the experiment without 208 enzymes, and a total of $60 \%$ of the lutein remained regardless of meal.

209 Figure 2 demonstrates the loss of lycopene during digestion. In the absence of enzymes (Figure 210 2A), gradual loss of lycopene was observed at each stage, resulting in a 35\% overall loss post211 jejunal phase. The presence of metmyoglobin or ferrous sulfate did not significantly alter lycopene 212 degradation at any digestion stage. In comparison, the experiment with enzymes (Figure 2B) 213 revealed no change in lycopene levels with lycopene alone or lycopene + ferrous sulfate until the 214 jejunal phase, where a $20 \%$ loss was observed. In contrast, a more pronounced lycopene loss was 215 observed after the duodenal and jejunal phases (12\% and 19\%, respectively) in the presence of 216 metmyoglobin.

217 The loss of $\beta$-carotene during digestion is shown in Figure 3. In the absence of enzymes 218 (Figure 3A), an immediate $20 \%$ post-gastric loss of $\beta$-carotene was observed under all meal 219 conditions, but there was no further significant $\beta$-carotene loss when alone or together with ferrous 220 sulfate during the rest of the experiment. In contrast, an additional $20 \%$ of $\beta$-carotene was lost in 221 the presence of metmyoglobin during the duodenal phase. In the presence of enzymes (Figure 3B), 222 a $25 \%$ loss of $\beta$-carotene when alone was observed post-gastric phase, but no additional significant 223 loss was observed through the duodenal and jejunal phases. When ferrous sulfate was added 224 together with $\beta$-carotene, this resulted in a $\sim 40 \% \beta$-carotene loss during the gastric phase, but no 225 further loss through the duodenal and jejunal phases was observed. By comparison, when 226 metmyoglobin was added to $\beta$-carotene, a 50\% $\beta$-carotene loss was observed during the gastric 227 phase and a further 30\% loss from initial $\beta$-carotene level during the duodenal phase of digestion. 
No significant change in \% cis-isomers was observed between the starting material and the

229 jejunal phase for any of the 3 carotenoids tested. Thus, the bars in Figures 1, 2, and 3 represent

230 total carotenoid (i.e. the summation of all-trans + cis isomers) at each stage.

\section{4. Discussion}

The relative susceptibility of these three carotenoids to loss under various conditions of digestion presents some intriguing results. We begin by comparing the behavior of carotenoids

234 alone digested without enzymes, as compared to carotenoids digested with enzymes (solid bars, A

235 vs. B in Figures 1, 2, and 3). Our experiments clearly reveal that a greater percentage of lutein and

236 lycopene survived the gastric and duodenal phases of digestion in the presence of enzymes, as

237 compared to the experiments without enzymes. In the experiments with enzymes, lipases and bile

238 salts work in concert to reduce the size of emulsified lipid droplets and create mixed micelles

239 during the duodenal phase. ${ }^{39}$ In contrast, the digestion experiments without enzymes were

240 performed to better understand the impact of chemical conditions alone on carotenoid degradation.

241 Thus, these experiments contained the emulsified test meal throughout each phase. Studies on the

242 stability of $\beta$-carotene - $^{40,41}$ and lutein ${ }^{40}$ emulsions have demonstrated that carotenoid stability is 243 directly proportional to lipid droplet size. Consequently, we expected the larger emulsified lipid

244 droplets produced in the experiments without enzyme to be more protective than small particle

245 micelles in the experiments with enzymes. Therefore, it was initially quite surprising to observe

246 no difference in $\beta$-carotene degradation, and a more rapid lutein and lycopene degradation in the

247 experiments without enzymes. However, the enzyme experiments also contained various proteins,

248 such as amylase during the initial sample treatment, pepsin added during the gastric phase, and the

249 porcine pancreatin preparation added during the duodenal phase. Previous in vitro studies have

250 demonstrated that certain whey proteins further protect $\beta$-carotene ${ }^{41}$ and lutein ${ }^{40}$ from degradation 
251 in emulsification model systems, as these proteins are believed to rest at the interface between the

252 lipid droplet and the aqueous solution. ${ }^{41}$ Similarly, a whey-protein encapsulated lycopene has been

253 shown to successfully deliver lycopene in humans, presumably via at least partial protection of

254 lycopene through gastro-intestinal conditions. ${ }^{42}$ In short, our results suggest that protein solutions

255 confer additional protection to lutein and lycopene against chemical oxidation during the gastric

256 and duodenal phases of digestion, but any advantage gleaned from protein is lost during the jejunal

257 phase (likely due to carotenoid transfer to and retention in less-protective micelles).

$\beta$-carotene was equally susceptible to degradation, regardless of the absence or presence of enzymes (solid bars, Figure 3A vs. 3B). It should be noted that these experiments with $\beta$-carotene were repeated (with the repeat experiments also performed in triplicate), with the same average $\beta$ carotene level and variability observed each time. Previous research has demonstrated that the \% carotenoid transferred from emulsion lipid droplet to micelle is inversely proportional to 263 carotenoid hydrophobicity, with lutein $>\beta$-carotene $>$ lycopene. ${ }^{39}$ Thus, we would expect that any 264 “emulsion effect" would more dramatically impact lutein as compared to $\beta$-carotene. Similarly, 265 we would anticipate that protein confers the same type of protection to $\beta$-carotene as compared to 266 lutein or lycopene. ${ }^{41}$ Thus, it is not clear why no difference in $\beta$-carotene was observed regardless 267 of the absence or presence of enzymes.

Of those tested, lycopene alone was found to be the most stable carotenoid through the entire digestive process with enzymes, with a $20 \%$ loss overall. In contrast, $40 \%$ of lutein alone 270 and $\beta$-carotene alone were lost during their respective digestions with enzymes. The lycopene and $271 \beta$-carotene results are in good agreement with Blanquet-Diot et al., who reported a $20 \%$ and $\sim 30 \%$ 272 loss, respectively using a dynamic in vitro digestion model. ${ }^{43}$ In contrast, Courraud et al., reported 273 a $50 \%$ loss of $\beta$-carotene after the gastric phase, and a further $20 \%$ loss during the intestinal 
274 phase $^{44}$. These differences in $\beta$-carotene stability are likely due to Courraud et al.'s direct 275 application of $\beta$-carotene dissolved in acetone to the mimicked digesta, and a much lower $\mathrm{pH}$ of 2 276 used during a prolonged gastric phase. ${ }^{44}$ Lutein loss was similar to that reported by Courraud et al. 277 in raw spinach. ${ }^{44}$ Other studies by Blanquet-Diot et al., and Chitchumroonchokchai et al., observed 278 no change in lutein levels over the course of in vitro digestion ${ }^{43,45}$. It is likely that the use of a 279 tomato food matrix ${ }^{43}$ and the absence of a jejunal digestion phase ${ }^{45}$ are the source of this 280 divergence.

Regardless of the presence or absence of enzymes, ferrous sulfate had no additional impact 282 on carotenoid loss during the experiments (white bars, Figures 1, 2, and 3). Previous work by our 283 group has demonstrated that in a gastric-like micellar model, increasing levels of ferrous iron 284 relative to $\beta$-carotene (0-10 equivalents) result in increasing levels of $\beta$-carotene oxidation, as 285 compared to no iron. However, excess levels of ferrous iron relative to $\beta$-carotene (50 equivalents) 286 resulted in an initial oxidative loss of $\beta$-carotene over 5-10 min, but surprisingly less $\beta$-carotene 287 oxidation through $120 \mathrm{~min}$. It was postulated that when ferrous iron is present in excess, various 288 perferryl and ferryl intermediates are formed, which further react with ferrous iron to produce high 289 levels of a diferric ether product, which is inert. ${ }^{15}$ The dose of ferrous sulfate and carotenoid used 290 in this study were calculated to reproduce a plausible scenario of a single iron tablet prescribed as 291 a supplement (delivering $80 \mathrm{mg}$ of divalent iron) consumed with a meal containing $20 \mathrm{mg}$ 292 carotenoid. Under these conditions, the iron to carotenoid equivalent is 37 for meals containing 293 lycopene or $\beta$-carotene + ferrous sulfate, and 39 for meals containing lutein + ferrous sulfate. Based 294 upon our results, we speculate that the ferrous sulfate levels were sufficiently high to result in the 295 formation of inert diferric ether, resulting in no additional carotenoid oxidation in these groups. It 
296 is also possible that the gelatin coating and maltodextrin excipient of the iron tablet exerted a 297 protective carotenoid effect during the initial phase of digestion. ${ }^{46}$

The concentration of metmyoglobin used in our studies $(40 \mu \mathrm{M})$ is reflective of the quantity 299 expected from the consumption of a $255 \mathrm{~g}(9 \mathrm{oz}$.) beef steak (estimated to deliver $30-50 \mu \mathrm{M}$ metmyoglobin). ${ }^{47-49}$ In the in vitro experiments with enzymes, metmyoglobin had no impact on 301 lutein stability (striped bars, Figure 1B), but a more pronounced impact on carotene stability 302 (striped bars, Figures 2B and 3B), especially that of $\beta$-carotene. These results are in good 303 agreement with similar work observing the capacity of various carotenoids to inhibit 304 metmyoglobin-induced peroxidation of linoleic acid in an emulsion model. ${ }^{16}$ bitory concentrations 305 at $50 \%$ of maximal linoleic acid peroxidation $\left(\mathrm{IC}_{50}\right)$ values were measured, and were shown to 306 follow the order of $\beta$-carotene $>$ lycopene $>$ xanthophylls derived from bacteria. ${ }^{16}$ In other words, 307 a larger concentration of $\beta$-carotene was needed to protect linoleic acid relative to the other 308 carotenoids. Further measures of the peroxide kinetics suggested that this difference may lie in the 309 fact that carotenes sit in the center of the lipid droplet, and thus their only mechanism of defense 310 is to halt further fatty acid peroxide propagation. In contrast, bacterial xanthophylls sit at the lipid311 water interface and likely inhibit peroxidation initiation altogether. ${ }^{16}$ It is not clear why $\beta$-carotene 312 was more sensitive than lycopene to metmyoglobin-induced oxidation. It is possible that at the 313 concentrations of lycopene used, lycopene microcrystals may have formed in the digesta mixture ${ }^{50}$, 314 which may have conferred physico-chemical protection, while $\beta$-carotene likely remained 315 dissolved. We intentionally used un-stripped sunflower oil in all of our experiments to create a 317 realistic liquid beverage that would be safe for use in a human clinical study. However, the 318 endogenous tocopherols and tocotrienols present likely protected carotenoids and reduced losses 
319 due to oxidation, as studies have previously demonstrated that alpha-tocopherol protects 320 lycopene ${ }^{51,52}, \beta$-carotene $e^{53}$, and lutein ${ }^{40}$ from various forms of oxidation in emulsion systems.

321 It should be noted that under typical digestive conditions (i.e. with enzymes), levels of lutein 322 alone and lycopene alone were not significantly different from the initial meal through the 323 duodenal phase. Immunohistochemical staining demonstrates the presence of apical membrane 324 transporters SR-B1 and CD-36 in the duodenum and jejunum of humans ${ }^{54}$, with Western blotting 325 showing significantly higher SR-B1 protein expression in the duodenum ${ }^{55}$ and higher expression 326 of CD-36 in the jejunum ${ }^{56}$ of rodents. Thus, we anticipate a fair portion of lutein and lycopene to 327 be absorbed in the duodenum (before degradation), and any resulting loss in the jejunum would 328 probably have a limited impact on overall bioavailability. However, our results suggest that partial 329 degradation of $\beta$-carotene alone under these types of meal conditions may ultimately reduce the 330 quantity of $\beta$-carotene that is bioavailable.

331 We noted no significant change from the initial \% cis isomers to the \% cis isomers remaining 332 in jejunal phase. These results are in good agreement with previous studies using static in vitro 333 digestion, which have demonstrated that the \% cis isomer contribution to total carotenoid content 334 is well maintained for lycopene ${ }^{57,58}$, lutein ${ }^{59}$, and $\beta$-carotene. ${ }^{60}$ These results are further 335 corroborated with human studies on gastric digesta for lycopene and $\beta$-carotene. ${ }^{61}$ The same 336 human study also investigated duodenal digesta, and found no change in lycopene but a slight 337 increase in $\%$ cis $\beta$-carotene (relative to starting $\%$ cis $\beta$-carotene). ${ }^{61} \mathrm{We}$ would attribute this 338 disparity to the dynamic nature of absorption in humans, and transporter selectivity for all-trans$339 \quad \beta$-carotene. ${ }^{62}$

340 While our primary objective was to understand carotenoid loss during digestion, we also 341 anticipated observing carotenoid degradation products in our samples. Indeed, the extraction and 
342 HPLC-PDA methods employed for the analysis of $\beta$-carotene- and lycopene-meal digesta would

343 have revealed the presence of $\beta$-apo-carotenals and apo-lycopenals, respectively, if they had been

344 present in sufficiently high quantities for PDA detection. Furthermore, previous work by our group

345 has demonstrated that under certain mimicked conditions of gastric digestion and in the presence

346 of metmyoglobin, $\beta$-apo-carotenals can be observed by PDA. ${ }^{15}$ However, no oxidation products

347 were observed in any of the samples in this study. This discrepancy with previous work may be

348 due to the previous use of non-biological surfactants (Tween 20 and Brij 35) to create micelle-like

349 conditions. ${ }^{15}$ Similarly, aldehydes have the capacity to react irreversibly with proteins to form

350 Schiff bases $^{63}$ and thus it is possible that aldehyde products were formed in our study, but were

351 not able to be extracted due to protein sequestration. While apo-carotenaldehydes were not

352 observed, the loss of lutein and lycopene in the jejunal phase, and the immediate loss of $\beta$-carotene

353 in the gastric phase, indicate that at least some derivatives were created. Further work is needed to

354 identify these products, and to determine if they are absorbed, and/or if they might have biological 355 effects in the jejunum or colon.

356 In conclusion, some of the chemical factors that reduce carotenoid stability in an in vitro

357 emulsion model are counteracted in the presence of digestive enzymes. In the presence of enzymes,

358 lutein and lycopene were robust to the effects of the digestive process throughout the gastric and

359 duodenal phases, with the most pronounced losses occurring during the jejunal phase. $\beta$-carotene

360 was most susceptible to degradation during the gastric phase, but no further loss was observed.

361 Our data suggests that a commonly prescribed dose of supplemental iron consumed with a 362 carotenoid-containing meal does not have an impact on carotenoid stability. However, co363 consumption of red meat with lycopene- or $\beta$-carotene-containing foods is likely to reduce the 364 quantity of carotenoid available for absorption, and may generate carotenoid oxidation products. 
365 Further work is needed to determine which products are produced, and whether they have 366 biologically relevant actions. 


\section{Conflict of Interest}

369 There are no conflicts of interest to declare.

370

371 Acknowledgements

372 We would like to thank Simona Birtic of Naturex, Inc. who kindly provided the lutein powder

373 and lycopene oleoresin used in this study. We would also like to thank Gisele Gellon of the

374 University of Grenoble Alpes (DCM UMR CNRS 5250, CS 40700, F-38058 Grenoble, France)

375 for providing the O-TRENSOX®. This work was supported by a grant from the PACA

376 (Provence-Alpes-Côte d'Azur) region. Rachel Kopec received support from the European

377 Union, in the framework of the Marie-Curie FP7 COFUND People Programme, through the

378 award of an AgreenSkills fellowship (under grant agreement $n^{\circ}$ 267196).

379

380 Abbreviations:

381 DCM dichloromethane

382 HPLC high-performance liquid chromatography

383 LC-MS liquid chromatography-mass spectrometry

$384 \mathrm{MeOH}$ methanol

385 MTBE methyl tert-butyl ether

386 PDA photodiode array detection 


\section{References}

3891 E. Giovannucci, Tomatoes, tomato-based products, lycopene, and cancer: review of the 390 epidemiologic literature, J. Natl. Cancer Inst., 1999, 91, 317-331.

3912 H. D. Sesso and J. M. Gaziano, Heart and vascular diseases, in Carotenoids in Health and 392 Disease, Marcel Dekker, New York, 2004, pp. 491-502.

$393 \quad 3$ B. Halliwell, Oxidative stress and cancer: have we moved forward?, Biochem. J., 2007, $394 \quad 401,1-11$.

3954 N. R. Madamanchi, A. Vendrov and M. S. Runge, Oxidative stress and vascular disease, 396 Arterioscler. Thromb. Vasc. Biol., 2005, 25, 29-38.

3975 M. F. Beal, Aging, energy, and oxidative stress in neurodegenerative diseases, Ann. $398 \quad$ Neurol., 1995, 38, 357-366.

3996 N. I. Krinsky, Carotenoids and cancer in animal models, J. Nutr., 1989, 119, 123-126.

4007 W. Stahl and H. Sies, Lycopene: A biologically important carotenoid for humans?, Arch. 401 Biochem. Biophys., 1996, 336, 1-9.

4028 A. Cantrell, D. J. McGarvey, T. George Truscott, F. Rancan and F. Böhm, Singlet oxygen 403 quenching by dietary carotenoids in a model membrane environment, Arch. Biochem.

$404 \quad$ Biophys., 2003, 412, 47-54.

4059 J. E. Romanchik, D. W. Morel and E. H. Harrison, Distributions of carotenoids and $\alpha-$ 406 tocopherol among lipoproteins do not change when human plasma is incubated in vitro, $J$. $407 \quad$ Nutr., 1995, 125, 2610-2617.

40810 S. Stanner, J. Hughes, C. Kelly and J. Buttriss, A review of the epidemiological evidence 409 for the "antioxidant hypothesis," Public Health Nutr., 2004, 7, 407-422. 
41011 C. A. Rice-Evans, J. Sampson, P. M. Bramley and D. E. Holloway, Why do we expect

411 carotenoids to be antioxidants in vivo?, Free Radic. Res., 1997, 26, 381-398.

41212 S. A. R. Paiva and R. M. Russell, $\beta$-Carotene and other carotenoids as antioxidants, J. Am.

$413 \quad$ Coll. Nutr., 1999, 18, 426-433.

41413 B. Halliwell, K. Zhao and M. Whiteman, The gastrointestinal tract: A major site of 415 antioxidant action?, Free Radic. Res., 2000, 33, 819-830.

41614 J. Kanner and T. Lapidot, The stomach as a bioreactor: dietary lipid peroxidation in the 417 gastric fluid and the effects of plant-derived antioxidants, Free Radic. Biol. Med., 2001, 31, $418 \quad 1388-1395$.

41915 C. Sy, O. Dangles, P. Borel and C. Caris-Veyrat, Iron-induced oxidation of (all-E)- $\beta$ 420 carotene under model gastric conditions: kinetics, products, and mechanism, Free Radic. $421 \quad$ Biol. Med., 2013, 63, 195-206.

42216 C. Sy, C. Caris-Veyrat, C. Dufour, M. Boutaleb, P. Borel and O. Dangles, Inhibition of 423 iron-induced lipid peroxidation by newly identified bacterial carotenoids in model gastric 424 conditions: comparison with common carotenoids, Food Funct., 2013, 4, 698-712.

42517 P. Goupy, E. Reynaud, O. Dangles and C. Caris-Veyrat, Antioxidant activity of (all-E)426 lycopene and synthetic apo-lycopenoids in a chemical model of oxidative stress in the 427 gastro-intestinal tract, N. Journal Chem., 2012, 36, 575-587.

42818 E. Vulcain, P. Goupy, C. Caris-Veyrat and O. Dangles, Inhibition of the metmyoglobin429 induced peroxidation of linoleic acid by dietary antioxidants: Action in the aqueous vs. lipid $430 \quad$ phase, Free Radic. Res., 2005, 39, 547-563. 
43119 S. Kiokias, C. Dimakou and V. Oreopoulou, Activity of natural carotenoid preparations

432 against the autoxidative deterioration of sunflower oil-in-water emulsions, Food Chem.,

$433 \quad 2009,114,1278-1284$.

43420 S. Kiokias and T. Varzakas, Activity of flavonoids and $\beta$-carotene during the auto-oxidative

435 deterioration of model food oil-in water emulsions, Food Chem., 2014, 150, 280-286.

43621 E. Reboul, M. Richelle, E. Perrot, C. Desmoulins-Malezet, V. Pirisi and P. Borel,

437 Bioaccessibility of carotenoids and vitamin E from their main dietary sources, J. Agric.

$438 \quad$ Food Chem., 2006, 54, 8749-8755.

43922 K. H. van Het Hof, C. E. West, J. A. Weststrate and J. G. Hautvast, Dietary factors that

$440 \quad$ affect the bioavailability of carotenoids, J. Nutr., 2000, 130, 503-506.

44123 P. Borel, D. Preveraud and C. Desmarchelier, Bioavailability of vitamin E in humans: An $442 \quad$ update, Nutr. Rev., 2013, 71, 319-331.

44324 J. Dyerberg, P. Madsen, J. M. Møller, I. Aardestrup and E. B. Schmidt, Bioavailability of 444 marine n-3 fatty acid formulations, Prostaglandins Leukot. Essent. Fatty Acids, 2010, 83, $445 \quad 137-141$.

44625 M. Carail and C. Caris-Veyrat, Carotenoid oxidation products: From villain to saviour?, 447 Pure Appl. Chem., 2006, 78, 1493-1503.

44826 J. W. Erdman, N. A. Ford and B. L. Lindshield, Are the health attributes of lycopene related 449 to its antioxidant function?, Arch. Biochem. Biophys., 2009, 483, 229-235.

45027 A. Eroglu, D. P. Hruszkewycz, C. dela Sena, S. Narayanasamy, K. M. Riedl, R. E. Kopec,

451 S. J. Schwartz, R. W. Curley Jr and E. H. Harrison, Naturally occurring eccentric cleavage

452 products of provitamin A $\beta$-carotene function as antagonists of retinoic acid receptors, $J$.

$453 \quad$ Biol. Chem., 2012, 287, 15886-15895. 
45428 R. E. Kopec, K. M. Riedl, E. H. Harrison, R. W. Curley Jr, D. P. Hruszkewycz, S. K.

455 Clinton and S. J. Schwartz, Identification and quantification of apo-lycopenals in fruits,

456 vegetables, and human plasma, J. Agric. Food Chem., 2010, 58, 3290-3296.

45729 F. Khachik, C. J. Spangler, J. C. Smith, L. M. Canfield, A. Steck and H. Pfander,

458 Identification, quantification, and relative concentrations of carotenoids and their

459 metabolites in human milk and serum, Anal. Chem., 1997, 69, 1873-1881.

46030 G. Serratrice, H. Boukhalfa, C. Béguin, P. Baret, C. Caris and J.-L. Pierre, O-TRENSOX, a

461 New Tripodal Iron Chelator Based on 8-Hydroxyquinoline Subunits: Thermodynamic and

462 Kinetic Studies, Inorg. Chem., 1997, 36, 3898-3910.

46331 W. J. Bowen, The absorption spectra and extinction coefficients of myoglobin, J. Biol.

$464 \quad$ Chem., 1949, 179, 235-245.

46532 D. A. Garrett, M. L. Failla and R. J. Sarama, Development of an in vitro digestion method 466 to assess carotenoid bioavailability from meals, J. Agric. Food Chem., 1999, 47, 4301$467 \quad 4309$.

46833 B. Gleize, F. Tourniaire, L. Depezay, R. Bott, M. Nowicki, L. Albino, D. Lairon, E. Kesse469 Guyot, P. Galan, S. Hercberg and P. Borel, Effect of type of TAG fatty acids on lutein and 470 zeaxanthin bioavailability, Br. J. Nutr., 2013, 110, 1-10.

47134 G. A. Garzón, C.-E. Narváez-Cuenca, R. E. Kopec, A. M. Barry, K. M. Riedl and S. J.

472 Schwartz, Determination of carotenoids, total phenolic content, and antioxidant activity of 473 Arazá (Eugenia stipitata McVaugh), an Amazonian fruit, J. Agric. Food Chem., 2012, 60, $474 \quad 4709-4717$. 
47535 L. K. Henry, G. L. Catignani and S. J. Schwartz, Oxidative degradation kinetics of

476 lycopene, lutein, and 9-cis and all-trans $\beta$-carotene, J. Am. Oil Chem. Soc., 1998, 75, 823-

$477 \quad 829$.

47836 K. Fröhlich, J. Conrad, A. Schmid, D. E. Breithaupt and V. Böhm, Isolation and structural

479 elucidation of different geometrical isomers of lycopene, Int. J. Vitam. Nutr. Res., 2007, 77, $480 \quad 369-375$.

48137 V. Böhm, Use of column temperature to optimize carotenoid isomer separation by C30 high 482 performance liquid chromatography, J. Sep. Science, 2001, 24, 955-959.

$483 \quad 38$ R Core Team, R: A language and environment for statistical computing. R Foundation for 484 Statistical Computing, Vienna, Austria., 2013. . Available at: http://www.R-project.org/. 48539 V. Tyssandier, B. Lyan and P. Borel, Main factors governing the transfer of carotenoids 486 from emulsion lipid droplets to micelles, BBA - Mol. Cell Biol. L., 2001, 1533, 285-292.

48740 K. Frede, A. Henze, M. Khalil, S. Baldermann, F. J. Schweigert and H. Rawel, Stability and 488 cellular uptake of lutein-loaded emulsions, J. Funct. Foods, 2014, 8, 118-127.

48941 L. Cornacchia and Y. H. Roos, Stability of $\beta$-carotene in protein-stabilized oil-in-water 490 delivery systems, J. Agric. Food Chem., 2011, 59, 7013-7020.

49142 M. Richelle, K. Bortlik, S. Liardet, C. Hager, P. Lambelet, M. Baur, L. A. Applegate and E. 492 A. Offord, A food-based formulation provides lycopene with the same bioavailability to 493 humans as that from tomato paste, J. Nutr., 2002, 132, 404-408.

49443 S. Blanquet-Diot, M. Soufi, M. Rambeau, E. Rock and M. Alric, Digestive stability of 495 xanthophylls exceeds that of carotenes as studied in a dynamic in vitro gastrointestinal 496 system, J. Nutr., 2009, 139, 876-883. 
44 J. Courraud, J. Berger, J.-P. Cristol and S. Avallone, Stability and bioaccessibility of different forms of carotenoids and vitamin A during in vitro digestion, Food Chem., 2013, 136, 871-877.

45 C. Chitchumroonchokchai, S. J. Schwartz and M. L. Failla, Assessment of lutein bioavailability from meals and a supplement using simulated digestion and caco-2 human intestinal cells, J. Nutr., 2004, 134, 2280-2286.

46 D. J. Cox, D. R. Kearney, S. T. Kirksey Jr and M. J. Taylor, Oil-in-water dispersions of $\beta$ carotene and other carotenoids stable against oxidation prepared from water-dispersible beadlets having high concentrations of carotenoid, US6007856 A, 1999.

47 J. D. Love and A. M. Pearson, Metmyoglobin and nonheme iron as prooxidants in cooked meat, J. Agric. Food Chem., 1974, 22, 1032-1034.

48 H. B. Craig, T. N. Blumer, W. W. G. Smart and M. B. Wise, Evaluation of hemoglobin, myoglobin, blood oxygen content and organoleptic qualities of beef from steers fed grain on pasture or cut forage and grain in drylot, J. Animal Sci., 1966, 25, 1128-1132.

49 K. Sato and G. R. Hegarty, Warmed-over flavor in cooked meats, J. Food Sci., 1971, 36, 1098-1102.

50 D. J. McClements, Crystals and crystallization in oil-in-water emulsions: Implications for emulsion-based delivery systems, Adv. Colloid Interface Sci., 2012, 174, 1-30.

51 R. Bou, C. Boon, A. Kweku, D. Hidalgo and E. A. Decker, Effect of different antioxidants on lycopene degradation in oil-in-water emulsions, Eur. J. Lipid Sci. Technol., 2011, 113, 724-729.

52 C. S. Boon, Z. Xu, X. Yue, D. J. McClements, J. Weiss and E. A. Decker, Factors affecting lycopene oxidation in oil-in-water emulsions, J. Agric. Food Chem., 2008, 56, 1408-1414. 
53 M. Heinonen, K. Haila, A.-M. Lampi and V. Piironen, Inhibition of oxidation in 10\% oilin-water emulsions by $\beta$-carotene with $\alpha$ - and $\gamma$-tocopherols, J. Amer. Oil Chem. Soc., 1997, 74, 1047.

54 M. V. Lobo, L. Huerta, N. Ruiz-Velasco, E. Teixeiro, P. de la Cueva, A. Celdrán, A. Martín-Hidalgo, M. A. Vega and R. Bragado, Localization of the lipid receptors CD36 and CLA-1/SR-BI in the human gastrointestinal tract: towards the identification of receptors mediating the intestinal absorption of dietary lipids, J. Histochem. Cytochem., 2001, 49, $1253-1260$.

55 S. F. Cai, R. J. Kirby, P. N. Howles and D. Y. Hui, Differentiation-dependent expression and localization of the class B type I scavenger receptor in intestine, J. Lipid Res., 2001, 42, 902-909.

56 M. Chen, Y. Yang, E. Braunstein, K. E. Georgeson and C. M. Harmon, Gut expression and regulation of FAT/CD36: possible role in fatty acid transport in rat enterocytes, Am. $J$. Physiol. Endocrinol. Metab., 2001, 281, E916-E923.

57 M. L. Failla, C. Chitchumroonchokchai and B. K. Ishida, In vitro micellarization and intestinal cell uptake of cis isomers of lycopene exceed those of all-trans lycopene, J. Nutr, 2008, 138, 482-486.

58 M. Richelle, B. Sanchez, I. Tavazzi, P. Lambelet, K. Bortlik and G. Williamson, Lycopene isomerisation takes place within enterocytes during absorption in human subjects, $B r . J$. Nutr., 2010, 103, 1800-1807.

59 F. Granado-Lorencio, B. Olmedilla-Alonso, C. Herrero-Barbudo, B. Pérez-Sacristan, I. Blanco-Navarro and S. Blazquez-García, Comparative in vitro bioaccessibility of 
carotenoids from relevant contributors to carotenoid intake, J. Agric. Food Chem., 2007, 55, 6387-6394.

54460 M. G. Ferruzzi, J. L. Lumpkin, S. J. Schwartz and M. Failla, Digestive stability, 545 micellarization, and uptake of $\beta$-carotene isomers by Caco- 2 human intestinal cells, $J$. $546 \quad$ Agric. Food Chem., 2006, 54, 2780-2785.

54761 V. Tyssandier, E. Reboul, J.-F. Dumas, C. Bouteloup-Demange, M. Armand, J. Marcand, 548 M. Sallas and P. Borel, Processing of vegetable-borne carotenoids in the human stomach 549 and duodenum, Am. J. Physiol. Gastrointest. Liver Physiol., 2003, 284, G913-923.

55062 A. During, M. M. Hussain, D. W. Morel and E. H. Harrison, Carotenoid uptake and 551 secretion by CaCo-2 cells: $\beta$-carotene isomer selectivity and carotenoid interactions, $J$. $552 \quad$ Lipid Res, 2002, 43, 1086-1095.

55363 D. J. Tuma, T. Hoffman and M. F. Sorrell, The chemistry of acetaldehyde-protein adducts, 554 Alcohol Alcohol. Suppl., 1991, 1, 271-276.

55564 M. Armand, P. Borel, C. Dubois, M. Senft, J. Peyrot, J. Salducci, H. Lafont and D. Lairon, 556 Characterization of emulsions and lipolysis of dietary lipids in the human stomach, Am. J. 557 Physiol., 1994, 266, G372-381. 
559 Table 1. Composition of the test meals

\begin{tabular}{lr}
\hline Water & $90 \mathrm{~g}$ \\
Sucrose & $9 \mathrm{~g}$ \\
Phospholipid containing powder $^{\mathrm{a}, \mathrm{b}}$ & $150 \mathrm{mg}$ \\
Sunflower oil $^{2}$ & $3 \mathrm{~g}$ \\
Carotenoid-oil preparation $^{\mathrm{b}}$ & $0.3 \mathrm{~g}$ \\
\hline
\end{tabular}

560 a) Delivering $75 \mathrm{mg}$ of phospholipid derived from egg, to match the 1:40 ratio of

561 phospholipid to lipid representative of a western $\operatorname{diet}^{64}$.

562 b) See Materials and Methods for additional details.

563

564 


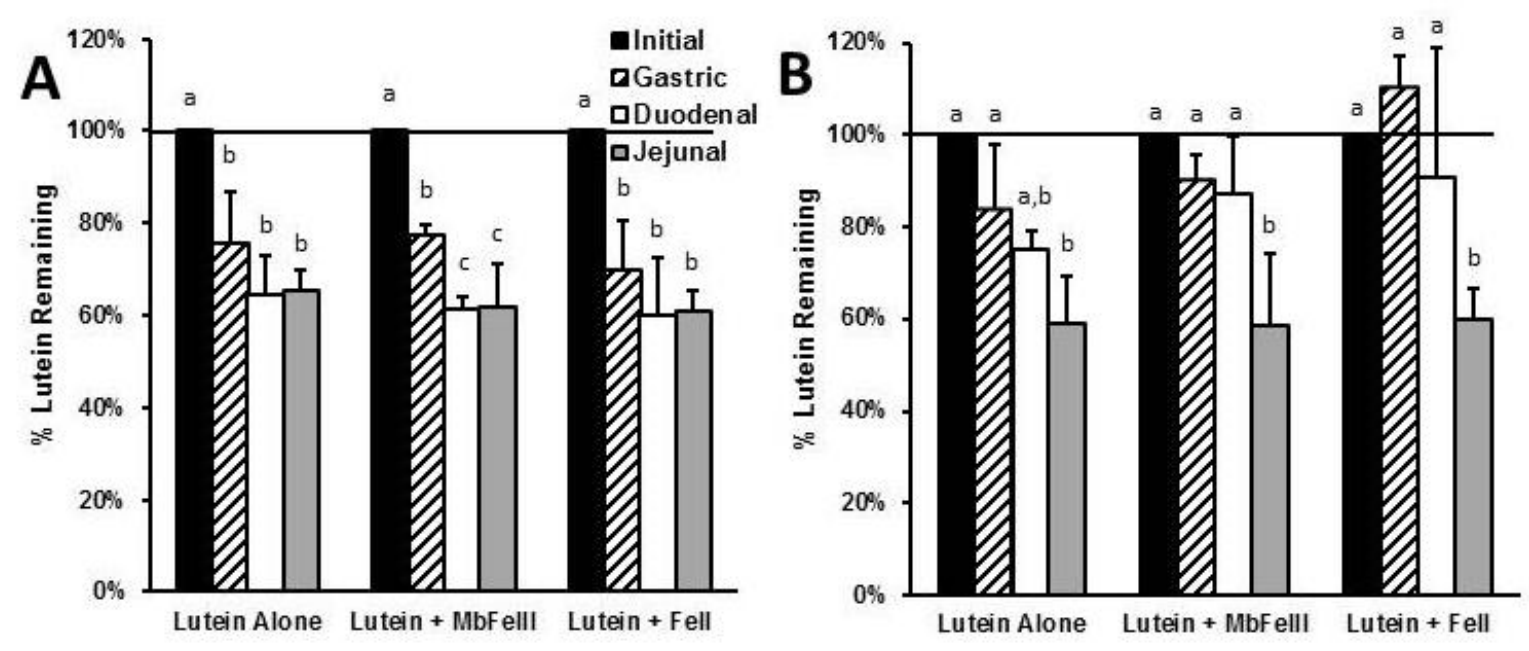

566 Figure 1. Loss of initial lutein through the gastric, duodenal, and jejunal phases of digestion in 567 the absence (A) and presence (B) of digestive enzymes. Bars represent average \% lutein \pm 568 standard deviation ( $\mathrm{n}=3$ for each meal). Different letters indicate statistically significant 569 differences within the same meal at different digestion phases $(P<0.05)$. There was no 570 significant difference between meal types at any of the digestion phases $(P<0.05)$. 

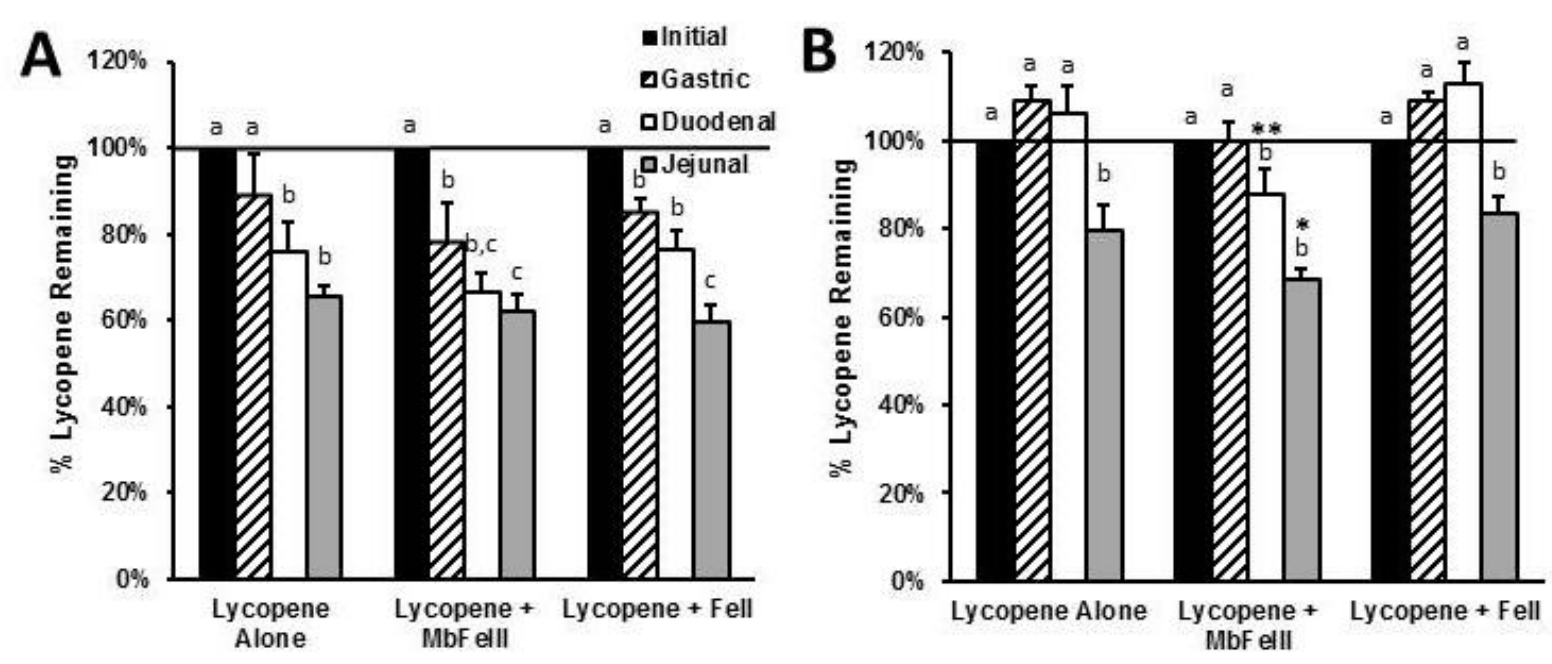

572

573 Figure 2. Loss of initial lycopene through the gastric, duodenal, and jejunal phases of digestion

574 in the absence (A) and presence (B) of digestive enzymes. Bars represent average \% lycopene \pm

575 standard deviation ( $\mathrm{n}=3$ for each meal). Different letters indicate statistically significant

576 differences within the same meal at different digestion phases $(P<0.05)$. Statistically significant

577 differences between meal types in the same digestion phase are noted with an asterisk, described

578 below.

$579 *$ Significantly different from Lycopene + FeII after the same digestion phase $(P<0.001)$

$580 * *$ Significantly different from Lycopene Alone and Lycopene + FeII after the same digestion

581 phase $(P<0.0001)$ 

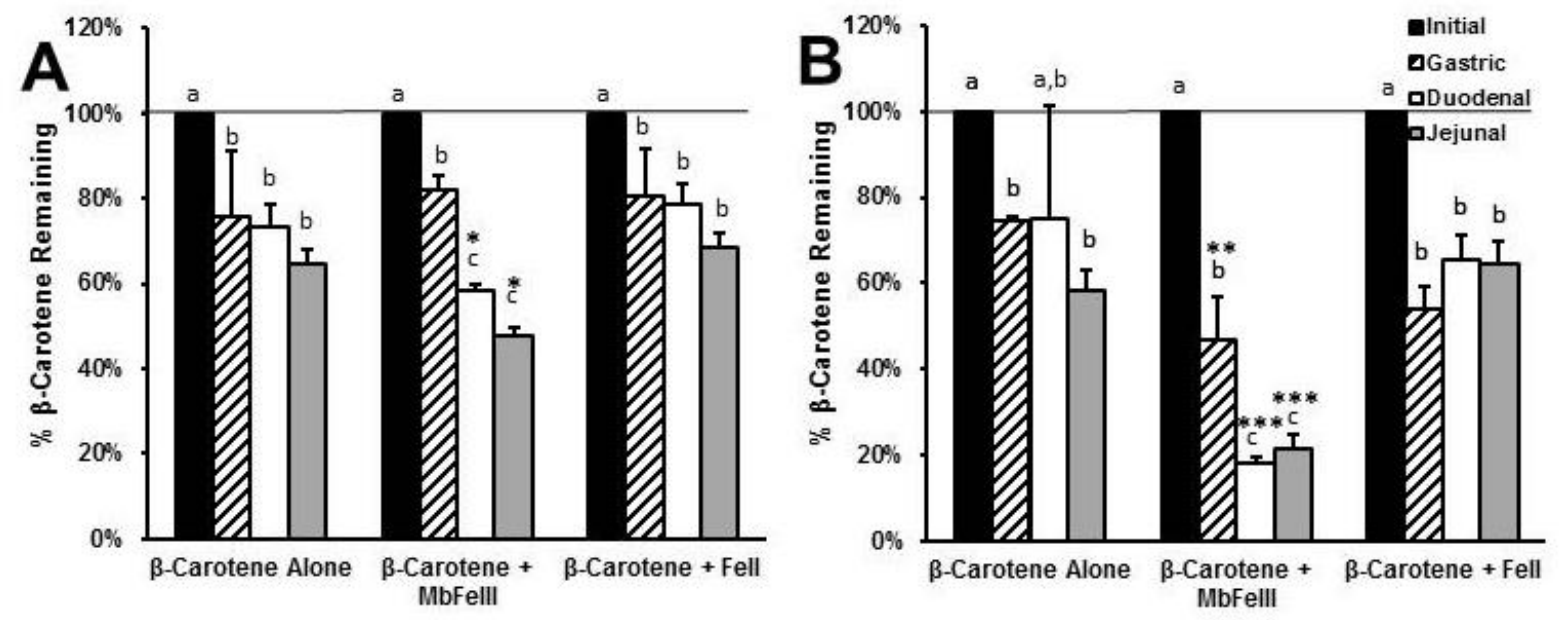

584 Figure 3. Loss of initial $\beta$-carotene through the gastric, duodenal, and jejunal phases of digestion 585 in the absence (A) and presence (B) of digestive enzymes. Bars represent average $\% \beta$-carotene \pm 586 standard deviation ( $\mathrm{n}=3$ for each meal). Different letters indicate statistically significant

587 differences within the same meal at different digestion phases $(P<0.05)$. Statistically significant 588 differences between meal types in the same digestion phase are noted with an asterisk, described 589 below.

$590 *$ Significantly different from $\beta$-Carotene + FeII after the same digestion phase $(P<0.005)$

$591 * *$ Significantly different from $\beta$-Carotene Alone after the same digestion phase $(P=0.006)$

$592 * * *$ Significantly different from $\beta$-Carotene Alone and $\beta$-Carotene + FeII after the same digestion 593 phase $(P<0.0001)$ 